\title{
Hazards of horse-riding as a popular sport
}

\author{
J. R. Silver FRCP (Ed \& Lond) ${ }^{1}$ and J. M. Lloyd Parry MA, MB BChir ${ }^{2}$ \\ ${ }^{1}$ National Spinal Injuries Centre, Stoke Mandeville Hospital, Aylesbury, UK \\ ${ }^{2}$ Honorary Medical Adviser to The Federation Equestre International (FEI) and the Governing Body of Horse \\ Trials (British Horse Society); Former Chairman of the Medical Equestrian Association
}

The increasing incidence of horse-riding accidents, which are often severe in nature, prompted a pilot study of a questionnaire designed to elucidate the cause of such accidents. It was hoped that, on a larger scale, the information gleaned would highlight possible preventative measures which might improve the safety of an important recreational pursuit enjoyed by young and old from many walks of life.

A retrospective study of riders sustaining serious spinal injuries admitted to Stoke Mandeville Hospital was compared with riders sustaining minor but significant injuries as the accidents came to the attention of the authors. The detailed analysis paid particular attention to the setting and to the experience and task of horse and rider.

It was found that $70 \%$ of the 20 accidents could be thought attributable to the behaviour of the horse at the time, and seven of these were in the spinal injuries group. Rider error was a significant contribution in seven cases, and in two instances the rider was under instruction at the time. There was also inadequate experience of the rider in seven cases, of which five were thought to show inadequate supervision.

The limited number of cases studied precludes significant observations, but, as the majority of accidents seemed preventable, a larger study has been initiated in collaboration with the British Horse Society.

Keywords: Horse-riding, nature of accident, survey

It has been estimated that there may be over three million riders in the UK of whom as many as one-third are children (Figure 1). It is a dangerous recreation as a large number of accidents occur; the British Horse Society is made aware of eight accidents per day involving horses and over one-third may result in head injuries ${ }^{1}$.

Horse-riding carries a high participant morbidity and mortality. Whereas a motor-cyclist can expect a serious incident at the rate of 1 per $7000 \mathrm{~h}$, the horse-rider can expect a serious accident once in every $350 \mathrm{~h}$, i.e. 20 times as dangerous as motorcycling ${ }^{2}$. Recent surveys have shown that $20 \%$ of injured riders attending hospital are admitted and approximately $60 \%$ of these have head injuries ${ }^{3-5}$.

Address for correspondence: Dr J. R. Silver, National Spinal Injuries Centre, Stoke Mandeville Hospital, Mandeville Road, Aylesbury, Bucks HP21 8AL, UK

(C) 1991 Butterworth-Heinemann Ltd.

0306-3674/91/020105-06
There are two different approaches to these figures. Enthusiastic riders argue that accidents are inevitable and that any activity which is worth doing carries a risk, which is viewed as an act of God. In contrast, there is the view of accident prevention experts, who believe that $90 \%$ of accidents are caused by human errors. Schneider ${ }^{6}$, in American football, has shown that accidents can be prevented if research is carried out exactly analogous to research in any other field, i.e. one has to identify the causative factors and then, having shown what they are, take steps to amend the conduct of the sport and so eliminate them.

There has been growing concern in the UK about the increasing number of accidents related to horse-riding $2-5,7,8$ and their severity, and we felt that, if a similar approach to that adopted by Schneider was used, they could be ameliorated. For this reason a collaborative retrospective study was undertaken.

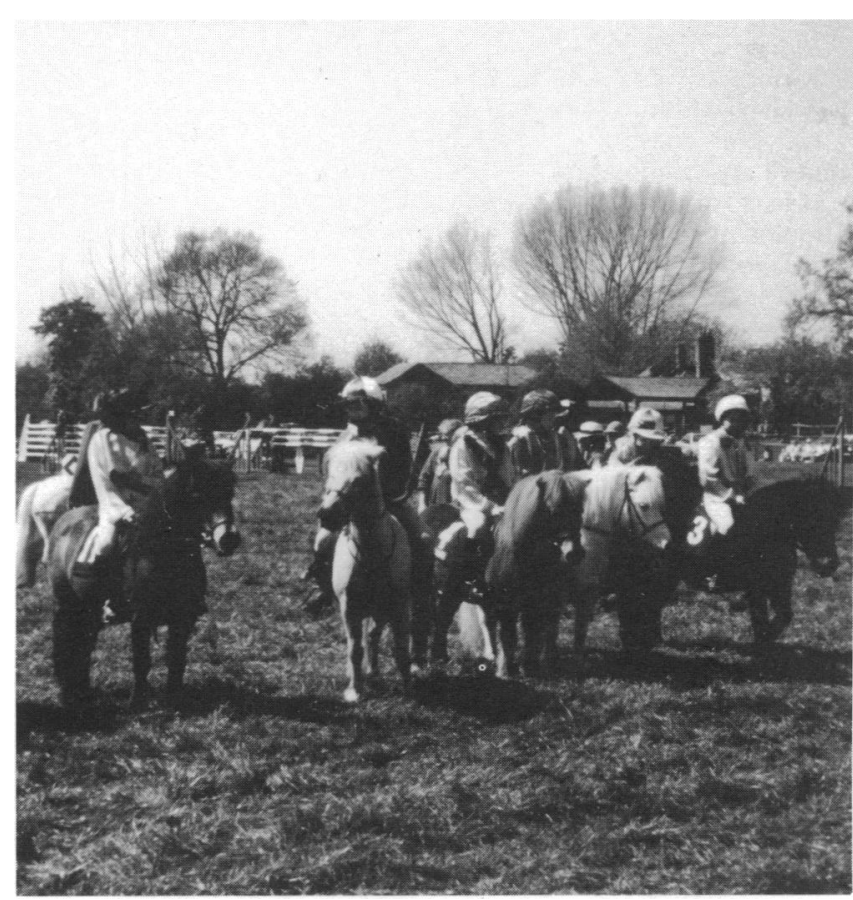

Figure 1. Children at play; competition starts at an early age 


\section{Methods}

A structured questionnaire included major factors thought to be responsible for accidents. The major accidents selected comprised those with severe spinal injuries and neurological complications, whilst the lesser accidents included those with fractures and minor head injuries. One doctor interviewed all the accident cases as quickly as possible, the majority within 1 week of injury, so that the accident and its circumstances were fresh in the rider's mind, though a number of the patients with serious spinal injuries were necessarily obtained from notes and interviewed some years after the accident.

Twenty accidents were analysed for details of the horse (Table 1), the rider (Table 2) and the circumstances and outcome of the accident (Table 3).

The horse. The factors included the age, sex, height, cost, condition, feed, usual behaviour and the type of equipment (tack) used.

The rider. The factors included the age, sex, medical history, current physical and psychological state,

Table 1. Details of the horses involved in the accidents causing spinal injuries or minor injuries

\begin{tabular}{|c|c|c|}
\hline \multirow[t]{2}{*}{ Details of horse } & \multicolumn{2}{|c|}{ Number of accidents } \\
\hline & Spinal & Minor \\
\hline Aged 8 years or less & 7 & 7 \\
\hline Aged 5 years or less & 3 & 4 \\
\hline Sex & 5 females & 9 females \\
\hline Height $>16$ hands & 5 & 6 \\
\hline Purchase value $>£ 1000$ & 3 (7 not known) & 6 ( 3 not known) \\
\hline Type TB (thoroughbred) & 5 & 3 \\
\hline $\begin{array}{l}\text { Three or more previous } \\
\text { owners }\end{array}$ & 2 (5 not known) & 1 ( 3 not known) \\
\hline \multicolumn{3}{|l|}{ Stabling } \\
\hline Riding school & 5 & 2 \\
\hline Farm & 2 & 4 \\
\hline $\begin{array}{l}\text { Exercised within } \\
\text { previous } 2 \text { days }\end{array}$ & 9 & 9 \\
\hline $\begin{array}{l}\text { Veterinary examination } \\
\text { prior to accident }\end{array}$ & 7 not known & 3 not known \\
\hline $\begin{array}{l}\text { Shoeing prior to } \\
\text { accident }\end{array}$ & 4 not known & 3 not known \\
\hline $\begin{array}{l}\text { Shoeing within previous } \\
6 \text { weeks }\end{array}$ & 4 & 6 \\
\hline $\begin{array}{l}\text { Feet condition thought } \\
\text { satisfactory }\end{array}$ & 7 (3 not known) & $\begin{array}{l}8 \text { (1 not known) } \\
(1 \text { shoe missing })\end{array}$ \\
\hline $\begin{array}{l}\text { Teeth condition thought } \\
\text { satisfactory }\end{array}$ & 7 (3 not known) & 8 ( 2 not known) \\
\hline $\begin{array}{l}\text { Sound, wind/limb/ } \\
\text { temper }\end{array}$ & 1 nasty tempered & 2 minor problems \\
\hline $\begin{array}{l}\text { Horse under treatment } \\
\text { Feed, hard and hay }\end{array}$ & $\begin{array}{l}1 \text { (3 not known) } \\
8\end{array}$ & $\begin{array}{l}1 \text { not known } \\
8\end{array}$ \\
\hline $\begin{array}{l}\text { Well behaved boxing } \\
\text { and grooming }\end{array}$ & 6 & 9 \\
\hline Good in traffic & 4 & 8 \\
\hline Good with other horses & 6 (2 not known) & 7 \\
\hline Competition experience & 2 & 3 \\
\hline Hazardous traits & 1 & 1 \\
\hline $\begin{array}{l}\text { Equipment, saddle, } \\
\text { bridle etc. good } \\
\text { condition }\end{array}$ & 9 & 10 \\
\hline Snaffle bit & 7 & 7 \\
\hline $\begin{array}{l}\text { Running martingale as } \\
\text { extra }\end{array}$ & 5 & 5 \\
\hline
\end{tabular}

Table 2. Details of the riders involved in accidents causing spinal injuries or minor injuries

\begin{tabular}{lrr}
\hline Details of rider & \multicolumn{2}{c}{ Number of accidents } \\
\cline { 2 - 3 } & Spinal & Minor \\
\hline Sex & & \\
Female & 7 & 7 \\
Male & 3 & 3 \\
Age & 4 & 2 \\
$<20$ years & 1 & 3 \\
$20-29$ & 2 & 4 \\
$30-39$ & 2 & 1 \\
$40-49$ & 1 & 0 \\
$>50$ & 2 & 2 \\
Previous head injury & 0 & 4 \\
Previous fractures & & 1 back pain \\
State of health at time of accident & 10 & 8 \\
Normally of calm temperament & 3 & 2 \\
Inexperienced & 9 & 8 \\
Previous qualified instruction & 8 & 8 \\
Good knowledge of stable management & 10 & 10 \\
Wearing hat and boots & 0 & 2 \\
BS 4472 jockey skull cap & 7 & 5 \\
Hat not secured or inadequate & 10 & 8 \\
Condition of personal equipment good & 5 & 6 \\
Carrying stick & 5 & 4 \\
Competitive experience & & \\
\hline
\end{tabular}

Table 3. The circumstances of the accident that led to spinal or minor injuries

\begin{tabular}{lll}
\hline Circumstances & \multicolumn{2}{c}{ Number of accidents } \\
\cline { 2 - 3 } & Spinal & Minor \\
\hline Spring & 2 & 0 \\
Summer & 5 & 2 \\
Autumn & 0 & 2 \\
Winter & 3 & 6 \\
am & 3 & 3 \\
pm & 7 & 7 \\
Dry weather & 10 & 9 \\
Indoors & 2 & 1 \\
Fall & & \\
Knocked off & 2 & 0 \\
Reared & 0 & 1 \\
Thrown & 5 & 6 \\
$\quad$ Unbalanced & 3 & 2 \\
At speed & 3 & 2 \\
Jumping & 4 & 4 \\
Preventable accident & 5 (possibly & $5(1$ not \\
& another 2) & known) \\
Accident happened at unapproved & 4 & 1 \\
riding stables & & \\
Experience adequate & 4 & 8 \\
Stress at the time or immediately & 4 & 1 \\
before & & \\
Type of spinal injury & & - \\
Cervical & 6 (C3/C4,1; & - \\
& C5/C6,2; & - \\
Thoracic & C6/C7,3) & - \\
$\quad$ Lumbar & T11/T12, & - \\
Minor fractures & 1 (L1) & - \\
Concussion & 0 & 6 \\
\hline & 0 & 3 \\
\hline
\end{tabular}


previous overall experience (e.g. in stable management and competitions) and the type of protective equipment used.

The accident. The factors included were the season, time of day, weather conditions, circumstances and place of accident, the medical aid available, the behaviour of the horse, the supervision and the history of drug intake. The rider's own description was recorded in detail, and was the usual basis of information.

\section{Results}

The common features of all these selected accidents can be exemplified as follows.

The typical accident is not related to traffic (Figure 2), occurs in the summer months, between 11.30 and 15.00 hours, during fine weather, when a relatively inexperienced rider (Figure 3), who may well have sustained a previous injury (eight of 20), falls from a mare that has been stabled in an unapproved riding establishment and sustains a fracture. The spinal injuries have most commonly been of the lower cervical spine and the subsequent first aid might be incorrect or inadequate, with a 50\% likelihood of subsequent litigation. In this typical accident the horse is excitable and the accident is caused by it becoming uncontrollable, most often at the canter but not necessarily jumping.

In this survey 14 accidents (of which seven were spinal injuries) were attributed to the behaviour of the horse and due principally to the excitement of the occasion (e.g. competition, hunting, fast riding), but in seven instances rider error played a significant role and on two occasions alarm occurred during riding instruction.

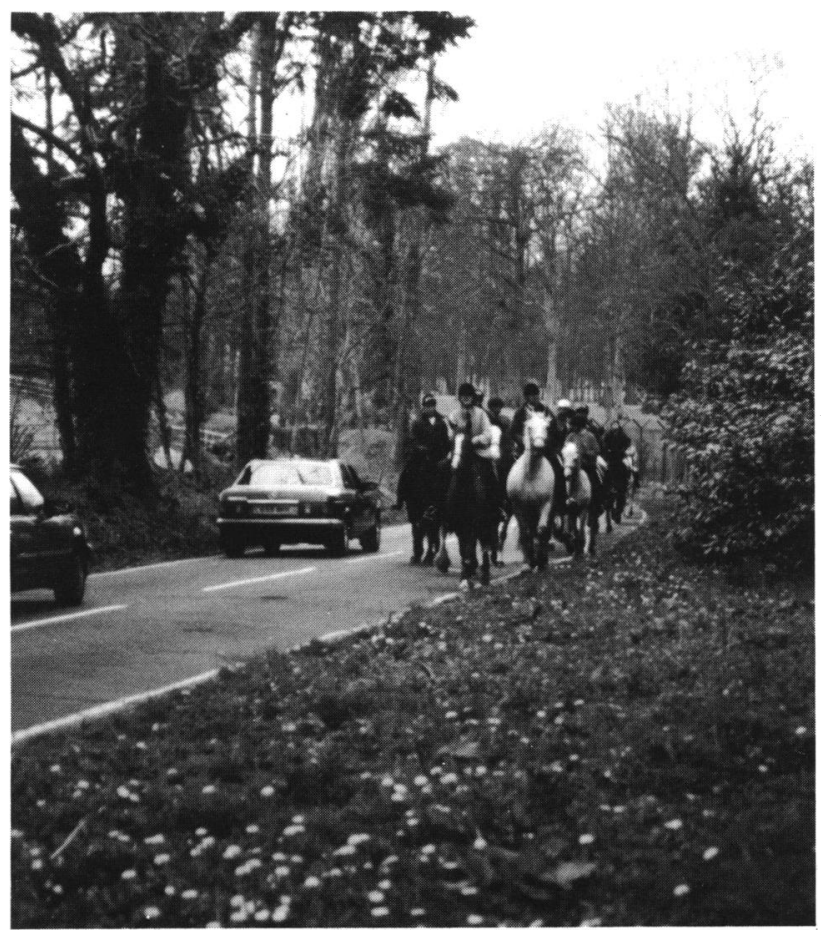

Figure 2. Congested highways in the UK and a lack of routes specifically for horse-riding leads to accidents

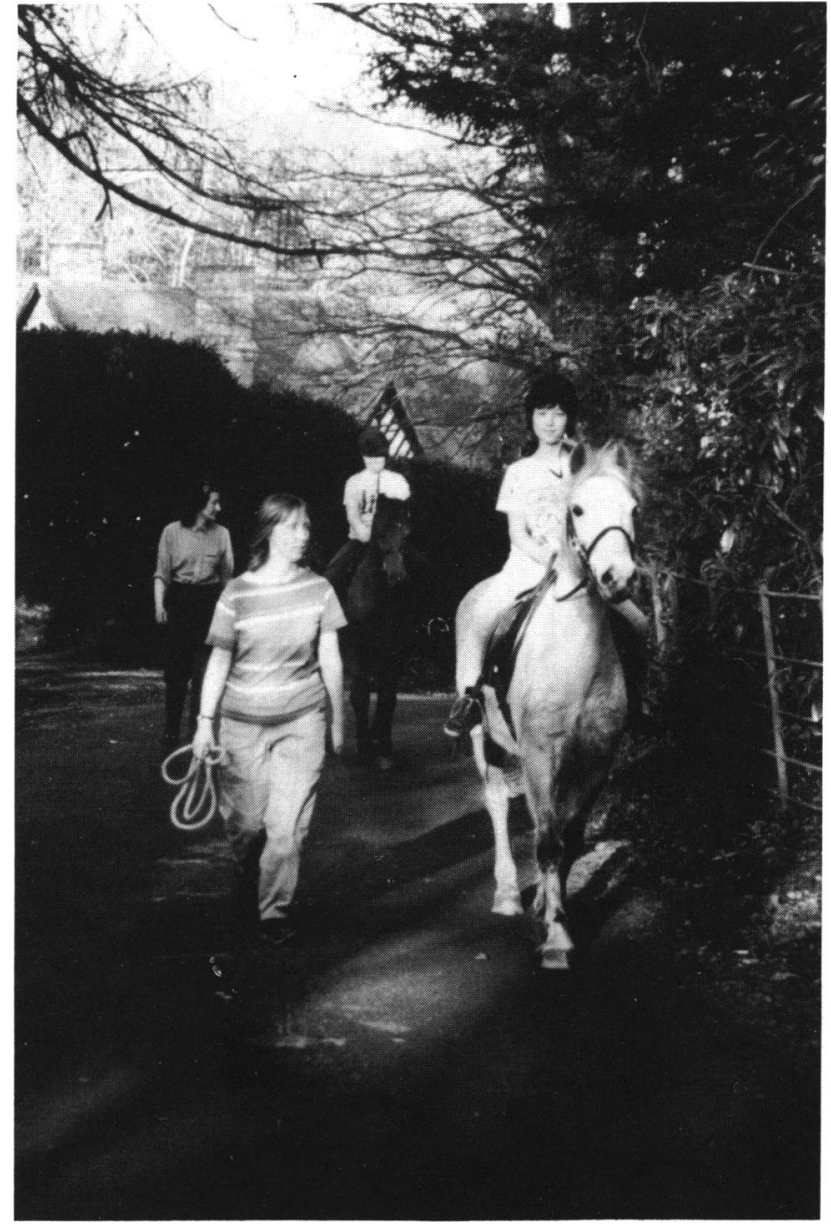

Figure 3. The correct supervision of child and pony; children need teaching

The experience of seven of the riders was inadequate, a mismatch to the capabilities of the horse, while in five the supervision seemed to be inadequate. In four cases alcohol had been consumed though not to excess.

The equipment was not found to be faulty in any case but the setup, in ten cases, was wrong. It was an 'accident waiting to happen', as the following two examples show.

\section{Case 1: Major accident}

In early summer a 28-year-old woman hired a relatively unfamiliar 9-year-old mare of 14.2 hands to enter a sponsored ride in aid of charity; it was a ride of several miles with obstacles. She had ridden the horse on five occasions but during the previous week she had been unsaddled by the branch of a tree whilst on another horse. On this occasion, having pulled her horse to one side of a fence, to avoid the rider ahead, she was again dislodged when bending low under a tree as she attempted to rejoin her companions. She fell in a sitting position with her legs out-stretched and immediately felt pins and needles and was aware of numbness from the waist downwards. She was able to wriggle her toes. A similar fall had occurred on one previous occasion and she had been kicked in the back 2 or 3 years previously. She was rolled onto a blanket and 
transferred to a stretcher for the ambulance journey to an Accident and Emergency Department. The next day she was transferred to a Spinal Injuries Unit with a wedge fracture of L1. She felt that her experience was inadequate for that type of riding and that she had been unwise to attempt it. The horse was too fast for her.

\section{Case 2: Minor accident}

A 24-year-old man, wearing a borrowed hat (Figure 4) and wellington boots, went for a riding lesson at the suggestion of his girlfriend. He was being taught on the lunge, with a horse he had ridden on two previous occasions, but now without saddle or stirrups. The horse had been attempting to bite another as their circles of progress were joined in the indoor school. After the horse of the other lesson had departed, the instructor encouraged this rider's horse to canter from the trot, the horse reared and he fell onto his right elbow, sustaining a fracturedislocation. He was driven to a local hospital by his girlfriend and has not ridden since. The qualifications of the instructor are not known.

A comparison of the two groups of accidents revealed that among the minor accidents the horses were better in traffic and more experienced. It is also noteworthy that four serious spinal injuries were incurred by those riders under the age of 20 . The

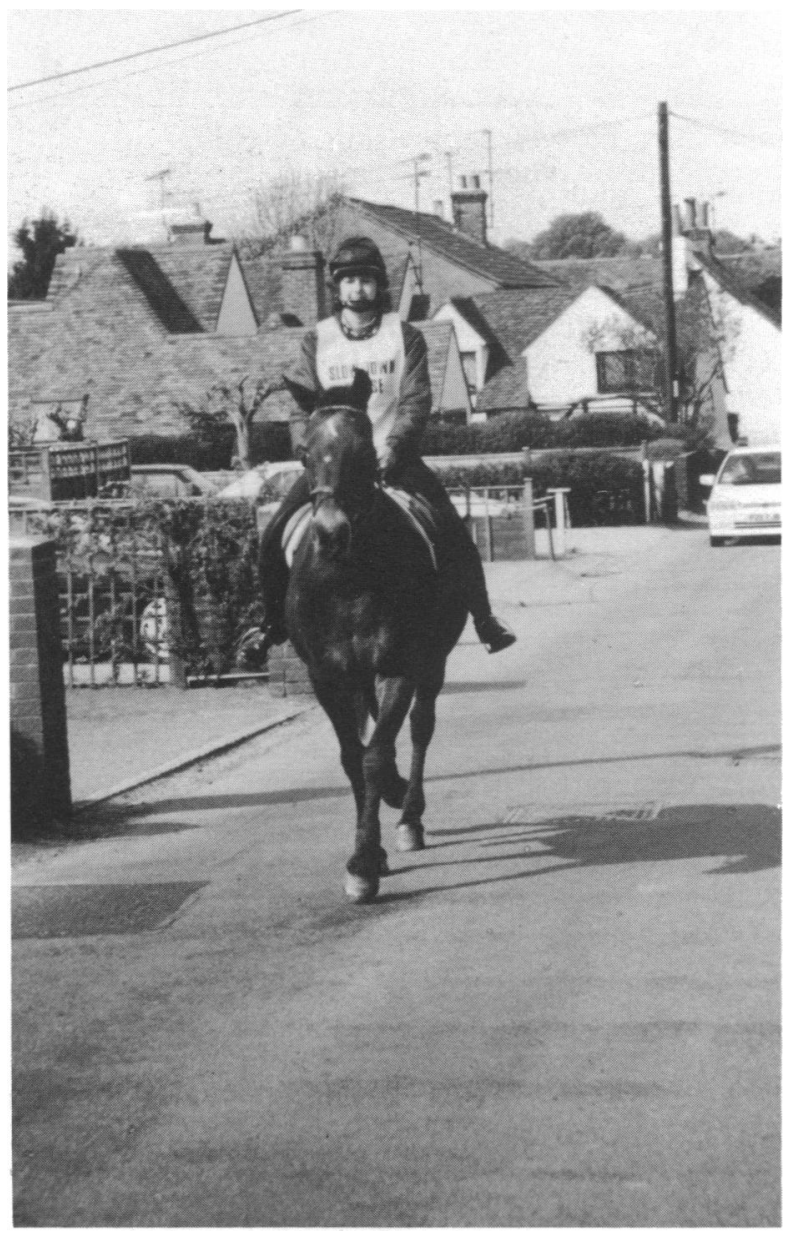

Figure 4. The correct safety equipment, reflective body vest, helmet and boots, but in built-up areas horses and cars do not mix

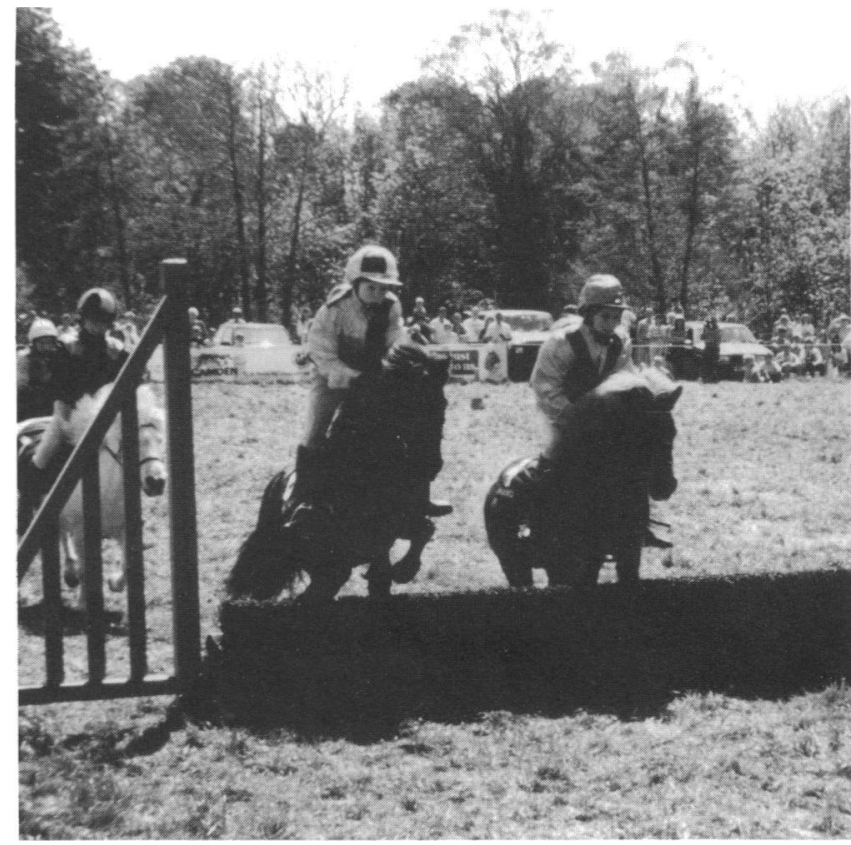

Figure 5. A mini Grand National for ponies; risks increase when leaving the ground

accidents in the major group occurred through the spring and summer, with four riders being under stress (Figure 5). The majority of accidents were preventable: ten were entirely preventable, two possibly so, but six were not preventable. There was insufficient information on the other two cases.

\section{Discussion}

Most accounts of horse-riding accidents have been drawn from riders attending Accident and Emergency departments. We do not know of any accounts dealing primarily with the circumstances of how the accident occurred and it is hoped that the design of this study, with its emphasis as outlined, will lead to valuable information in terms of prevention. The questionnaire was compiled after discussion with statistical, accident and equestrian experts; following a trial run, it was found that it produced all the factors that were relevant to the horse-riding accident.

The riders' major injuries are of some interest in that the fractures comprised six cervical, two thoracic and two lumbar, whilst six of the less serious group were associated with head injury. This is in contrast to the injuries sustained at rugby, gymnastics and trampolining which were almost entirely fractures or dislocations of the cervical spine. Much greater forces are operating when a rider falls from a height of $3 \mathrm{~m}$ (Figures 6, 7a and $b$ ) at speeds which can reach up to $65 \mathrm{~km} / \mathrm{h}$; also a rider may be subjected to the $500 \mathrm{~kg}$ (half a ton) weight of a horse during a fall (Figure 8) ${ }^{9}$.

Many impacts are not entirely directed to the head so that concentration only on the value of preventative headgear will not eliminate serious spinal injuries (Figure 9). Nevertheless, it must be stated that, of the six riders in the major accident group, all wore riding hats but none were wearing the jockey skull-cap (BS 4472). Of the three with concussion in 


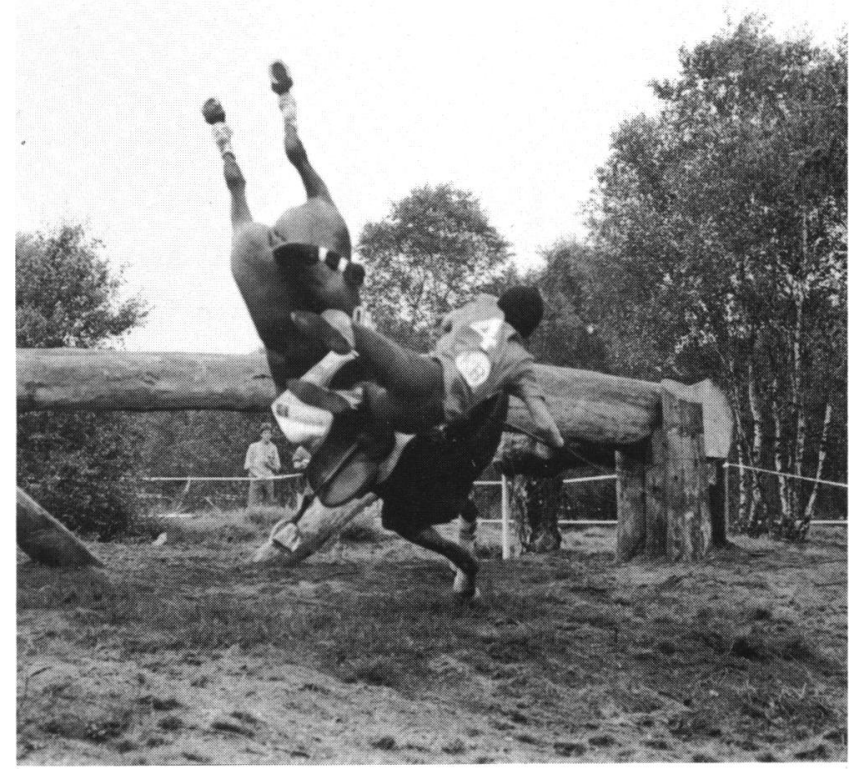

Figure 6. Falling during a jump will increase the height and the force exerted upon the body

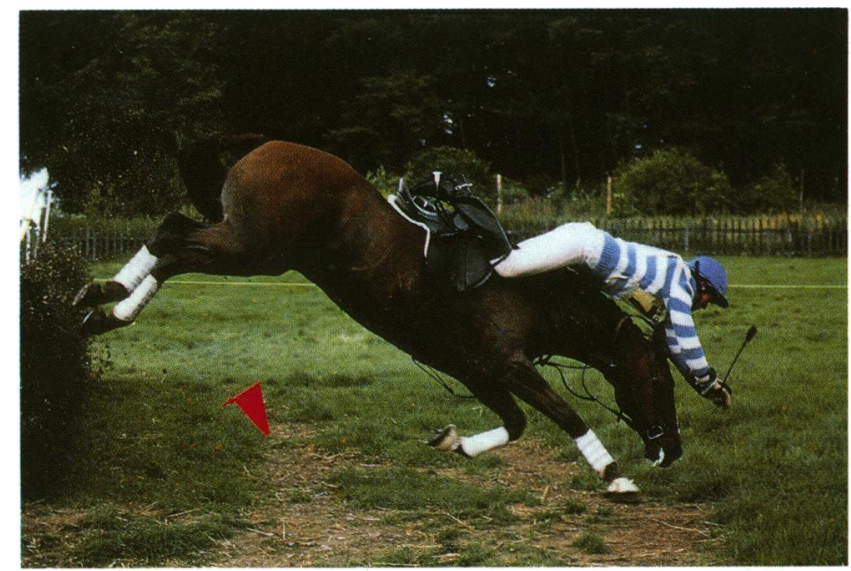

a

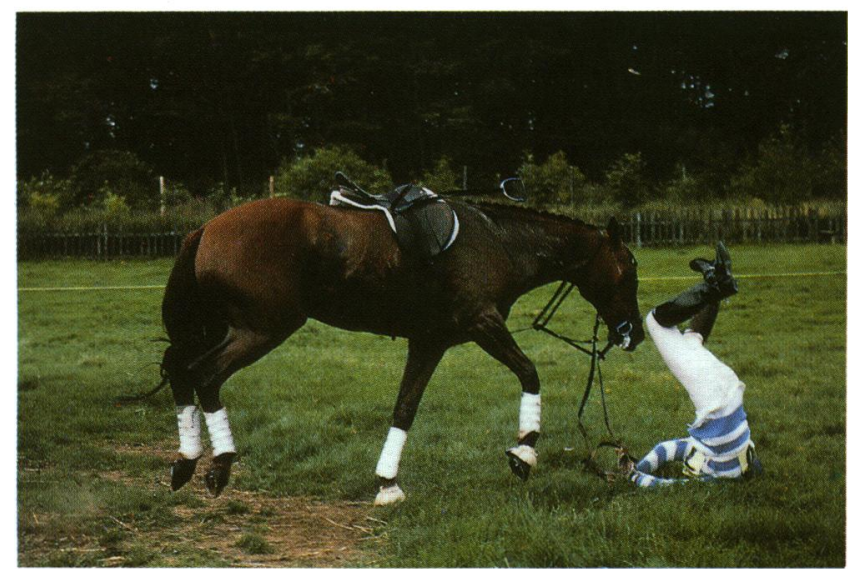

b

Figure $7 a$ and $b$. The head leads during many accidents, explaining why head and spinal injuries occur

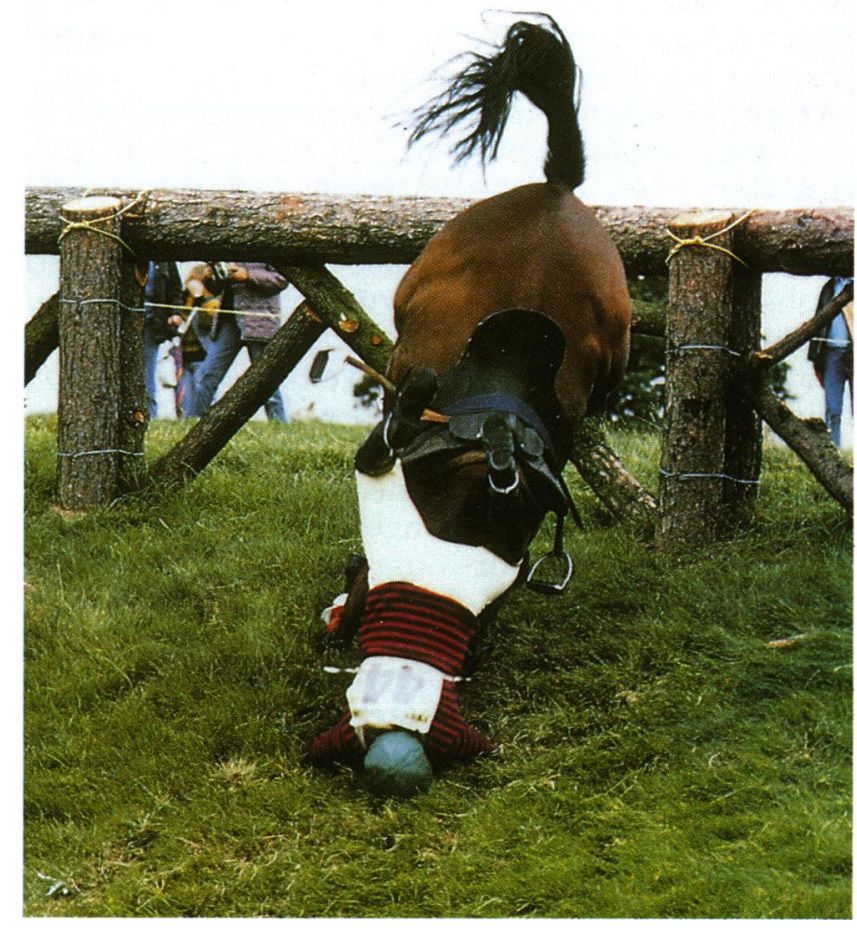

Figure 8. Another graphic example of the head and cervical spine being vulnerable

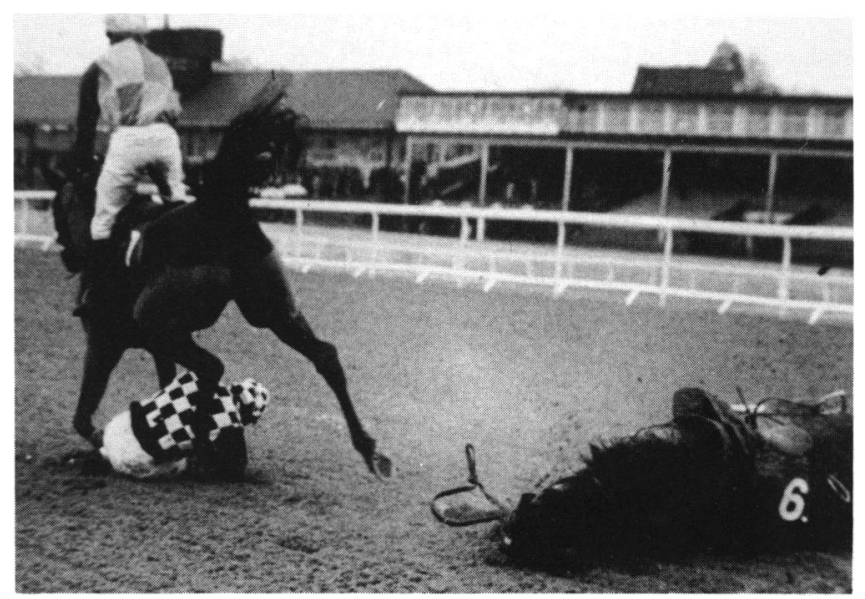

Figure 9. Having survived falling from a horse, the rider may be injured by another horse and kicked or trampled on

the minor group, one had an adequate, harnessed head protection. The main reason for such an accident was that the horse got out of control or failed to be controlled and then the rider was flung off. To understand why this happened at least three questions must be asked. Firstly, was the horse unridable by any rider? Secondly, was the horse unridable for that particular rider? Thirdly, was the horse ridable by that rider under certain situations but not in the type of situation that arose (e.g. too fast, too difficult a jump attempted or the rider, under stress, transmitting the anxiety to the horse)?

As the ride is at the instigation of the rider, it is the equestrian who should have control of the situation 
and be the only one to make judgements; this is the criterion by which these accidents must be judged, however clever the horse may be thought to be. It is noteworthy that seven of these riders were attending a riding establishment and, if under instruction, probably relied on the judgement of the people supervising them. In such a controlled environment, the unpredictability of the horse is at least countered by the experience of the instructor and this type of accident ought to have been much easier to prevent. The major accidents often involved striking a nearby solid object such as a perimeter wall of the arena or branches of trees.

Finally, it has been suggested that different forms of horse-riding are more dangerous than others, due to speed, jumping or unfamiliar terrain (as in hunting). It is intended that by using our questionnaire on a larger scale and drawing samples of accidents from widely different sources of horseriding disciplines that such facts can be established.

\section{Acknowledgements}

We should like to express our thanks to Mr N. Hickling, formerly of Loughborough University Department of Ergonomics, Dr Helen Muir of the Applied Psychology Unit of Cranfield School of Technology and to Miss Muriel Ambler BHSI and other equestrian experts for their invaluable advice. We are indebted to Brian Hill, Eventing Magazine, for Figures 7 and 8, and to Edward Whittaker,
Racing Post, for Figure 9. Under no circumstances do we overlook the major contribution of our injured riders, some of whose fortitude is an inspiration, nor do we forget the industry of our secretaries Mrs Gwen Tighe and Mrs Margaret Hughes.

\section{References}

1 Whitlock MR. Horse riding is dangerous for your health. Proceedings of the Second International Conference on Emergency Medicine, Brisbane, 1988 Australasian College for Emergency Medicine, 1988: 191.

2 Firth JR. Equestrian injuries. In: Schneider RC, Kennedy JC, Plant ML, Fowler PJ, Hoff FT, Matthews LS, eds. Sports Injuries, Mechanisms Prevention and Treatment. Baltimore: Williams and Wilkins, 1985: 431-8.

3 Barber HM. Horse play: survey of accidents with horses. $\mathrm{Br}$ Med J 1973; iii: 532-4.

4 Avery JG. Fact Sheet Child Accident Prevention Trust, London: 1986.

5 Lloyd RG. Riding and other equestrian injuries: considerable severity. Br J Sports Med 1987; 21: 22-4.

6 Schneider RC. Head and neck injuries in football. In: Schneider RC, Kennedy JC, Plant ML, Fowler PJ, Hoff FT, Matthews LS, eds. Sports Injuries, Mechanisms Prevention and Treatment. Baltimore: Williams and Wilkins, 1985: 1-3.

7 Muwanga LC, Dove AF. Head protection for horse riders: a cause for concern. Arch Emer Med 1985; 2: 85-7.

8 Whitlock MR, Whitlock J, Johnston B. Equestrian injuries: a comparison of professional and amateur injuries in Berkshire. Br J Sports Med 1987; 21: 25-6.

9 Miles JR. The racecourse Medical Officer. The Veterinary Record 1970; 87: 284-6. 